\title{
Richness and species composition of arboreal arthropods affected by nutrients and predators: a press experiment
}

Received: 28 June 2005 / Accepted: 5 December 2005/Published online: 20 January 2006

(C) Springer-Verlag 2006

\begin{abstract}
A longstanding goal for ecologists is to understand the processes that maintain biological diversity in communities, yet few studies have investigated the combined effects of predators and resources on biodiversity in natural ecosystems. We fertilized nutrient limited plots and excluded insectivorous birds in a randomized block design, and examined the impacts on arthropods associated with the dominant tree in the Hawaiian Islands, Metrosideros polymorpha (Myrtaceae). After 33 months, the species load (per foliage mass) of herbivores and carnivores increased with fertilization, but rarified richness (standardized to abundance) did not change. Fertilization depressed species richness of arboreal detritivores, and carnivore richness dropped in caged, unfertilized plots, both because of the increased dominance of common, introduced species with treatments. Herbivore species abundance distributions were more equitable than other trophic levels following treatments, and fertilization added specialized native species without changing relativized species richness. Overall, bird removal and nutrient addition treatments on arthropod richness acted largely independently, but with countervailing influences that obscured distinct top-down and bottom-up effects on different trophic levels. This study demonstrates that species composition, biological invasions, and the individuality of species traits may complicate efforts to predict the interactive effects of resources and predation on species diversity in food webs.
\end{abstract}

Communicated by Oswald Schmitz

D. S. Gruner · A. D. Taylor

Department of Zoology, University of Hawai'i at Mānoa, Hawai'i, USA

D. S. Gruner $(\bowtie)$

Bodega Marine Lab, University of California-Davis, 2099 Westside Rd, P.O. Box 247,

Bodega Bay, CA 94923-0247, USA

E-mail: dsgruner@ucdavis.edu

Tel.: + 1-707-8752022

Fax: + 1-707-8752009
Keywords Biological diversity - Distance-based linear models and nonparametric MANOVA .

Hawaiian Islands · Insectivorous birds ·

Top-down and bottom-up forces

\section{Introduction}

Theory and empirical evidence demonstrate that both resources ('bottom-up') and predators ('top-down') can influence species richness and community composition. For instance, increasing productivity from low levels is expected to increase diversity by allowing rare species to colonize new resources (MacArthur 1969; Abrams 1995) or persist in larger local populations less susceptible to demographic extinction (Hutchinson 1959; Wright 1983; Siemann 1998; Srivastava and Lawton 1998). Increasing productivity may also increase intraspecific density dependence (Abrams 1995; Siemann 1998) or population growth rates and resilience after disturbance (De Angelis 1980; Huston 1994; Cardinale et al. 2005). However, diversity may decline at extremely high resource levels, creating a hump-shaped pattern at local to regional scales (Rosenzweig and Abramsky 1993; Huston 1994; Rosenzweig 1995; Waide et al. 1999). Although generalities of the productivity-diversity relationship are still controversial (Abrams 1995; Mittelbach et al. 2003; Whittaker and Heegaard 2003), recent syntheses indicate that, at local scales, this pattern commonly is humpshaped in plant communities, but is more often a simple positive relationship within animal communities (Waide et al. 1999; Mittelbach et al. 2001).

Experimental manipulation of top predators has been shown to influence the diversity of prey (e.g., Paine 1966; Schoener and Spiller 1996), but community impacts vary depending on factors such as diet breadth, temporal and spatial scale, and food web structure (Sih et al. 1985; Holt and Lawton 1994). For example, generalist predators can depress diversity directly by extirpating rare species or those that occur in small ephemeral populations dependent on immigration (Schoener and Spiller 
1996; Spiller and Schoener 1998). Conversely, keystone predators can prey preferentially on dominant competitors or the most frequent prey, thereby mediating prey coexistence and indirectly increasing community richness (Paine 1966; Tilman 1986; Holt et al. 1994; Leibold 1996).

Multivariate models predict the effects of predators will interact with productivity to determine community diversity (Menge and Sutherland 1987; Huston 1994; Leibold 1996; Kondoh 2001). For instance, Leibold's (1996) graphical model hypothesized maximum species coexistence at intermediate levels of both resources and predation. However, qualitative predictions at more extreme bottom-up or top-down parameter levels can be contingent upon species traits, species turnover, and food web complexity. Empirical support for the essential prediction of several models (Leibold 1996; Kondoh 2001), an interactive effect of resources and predation on diversity, has been mixed: while top-down and bottom-up effects are often strong and opposing, they are not always interactive (Proulx and Mazumder 1998; Kneitel and Miller 2002; Worm et al. 2002; Dyer and Letourneau 2003; Hillebrand 2003). There is a clear continuing need for more research on top-down and bottom-up constraints on diversity of under-represented taxa (e.g., terrestrial invertebrates) in multifactor experimental designs. To our knowledge, Dyer and Letourneau (2003) provide the only multifactor manipulation of the effects of resources (light and nutrients) and consumers (predatory beetles) on terrestrial arthropod diversity.

We investigated the combined effects of productivity and bird predation pressure on the richness and composition of a species-rich arboreal arthropod community. A press experiment was carried out for 33 months on a 120-year-old basaltic lava flow on the island of Hawai'i. Nutrients are limiting to plant growth and productivity on this geologically young substrate, and are amenable to experimental fertilization (Raich et al. 1996; Gruner 2004b). Metrosideros polymorpha (Myrtaceae) is the only tree species that has colonized the thin soils at this site, and small stature but mature trees can be caged completely to exclude insectivorous birds. Our focus on the fauna of this single, dominant plant species controlled confounding impacts of altered plant species composition typically observed with increased productivity (Suding et al. 2005). Trophic level abundance and biomass responses have been reported previously (Gruner 2004b), but this study explores the individual and combined effects of resource and predator manipulations on arthropod species richness and composition. Fertilization was expected to increase richness and shift species composition across trophic levels. Bird exclusion could be expected to increase or decrease richness, depending on arthropod species composition, the prey selectivity of bird species, or ecosystem productivity (an interactive effect with the fertilization treatment).

\section{Materials and methods}

Site descriptions and study species

The experiments were located on a historical pāhoehoe lava flow of 1881 in the Upper Waiākea Forest Reserve, on the windward slope of Mauna Loa, Island of Hawai' $\mathrm{i}\left(19.664^{\circ} \mathrm{N}, 155.284^{\circ} \mathrm{W}\right)$. The site is a montane $(\sim 1,280 \mathrm{~m})$, early successional wet forest $(4,000 \mathrm{~mm}$ aap; Giambelluca et al. 1986) dominated by M. polymorpha Gaudichaud-Beaupré (Myrtaceae). A morphologically and physiologically plastic tree (Cordell et al. 2001), M. polymorpha is a widespread native to many habitats, the most abundant woody species at this site, and a key contributor to ecosystem biomass and productivity (Raich et al. 1997). Other common plants included native ferns [e.g. Dicranopteris linearis (Burm.) Underw. (Gleicheniaceae)], sedges [e.g. Machaerina angustifolia (Gaud.) T. Koyama (Cyperaeae)] and low shrubs [e.g. Coprosma ernodeoides A. Gray (Rubiaceae)]. Further site description was reported in Gruner (2004b).

The macrofauna associated with Metrosideros in Hawaii is limited to arthropods and birds. Leaf chewing and bud mining lepidopteran larvae, phloem and xylem feeding Heteroptera and Homoptera, and gall forming psyllids (Homoptera: Triozidae) were the most common phytophagous taxa at this site (Gruner 2004a). Invertebrate predators (e.g. Araneae, some Heteroptera and Coleoptera), hymenopteran parasitoids (Ichneumonidae, Bethyliidae, and Chalcidoidea) and diverse arthropod saprophages, fungivores, and microbivores (e.g., Psocoptera, Isopoda, Collembola, and some Coleoptera) are also present (Stein 1983; Gruner 2004a, b). Phytophagous groups are predominantly endemic species specialized to feeding on $M$. polymorpha, whereas numerous detritivorous, predaceous, and parasitic species are introduced (Gruner 2004a). Ecology and systematics of the mites (order Acari) are virtually unknown (but see Swift and Goff 2001).

Six passerines were observed in the region with regularity, three of which are insectivorous, the 'amakihi (Hemignathus virens), 'elepaio (Chasiempis sandwichensis), and Japanese white-eye (Zosterops japonicus). Two nectarivorous birds, the 'apapane (Himatione sanguinea) and 'i'iwi (Vestiaria coccinea), and one frugivorous thrush, the 'oma'o (Myadestes obscurus), also take arthropods to varying degrees, especially in the spring while provisioning nests (Perkins 1903; Baldwin 1953; van Riper and Scott 1979). Gut and fecal samples have shown that spiders and all major phytophagous insect families are well represented in the diets of these birds, whereas crustaceans (isopods) and small arthropods (e.g., Collembola, mites, and many parasitoids) were not commonly recovered (Baldwin 1953; Foster 2005, C. Ralph and C.J. Ralph, unpublished data). 


\section{Experimental design}

Fertilization and avian predator exclusion treatments were established in a $2 \times 2$ randomized block design. We laid out $20 \times 20 \mathrm{~m}$ plots, each separated at minimum by 10-m buffer strips, in pairs along an elevational transect. Before assigning treatments to plots, a clump of 1-6 trees was selected randomly from all possible clumps within the central $8 \times 8 \mathrm{~m}$ of each plot. Clumps were defined by one or more trees at least $2 \mathrm{~m}$ tall, but not taller than $3.5 \mathrm{~m}$. Trees taller than $4 \mathrm{~m}$ were unusual, but were excluded from consideration because they could not be caged (see below). There were a total of 88 focal trees randomly distributed among 32 plots within 8 blocks.

Within each block, plots were randomly assigned to the following treatment levels: (1) control, (2) fertilization only, (3) bird exclusion cage only, and (4) fertilization and cage. Beginning in September 1998 with a double loading dose, plots were hand fertilized at 6month intervals with nitrogen, phosphorus, and a broad spectrum of essential granular nutrients following the 'NPT' protocol of Raich et al. 1996 (Gruner 2004b). The final fertilization occurred in October of 2000.

Sixteen bird exclosure cages $(4 \mathrm{~m}$ tall $\times 4-6 \mathrm{~m}$ each side) were constructed in September 1998. Lightweight electrical conduit pipes were affixed onto steel rebar driven into the basalt substrate. Galvanized wire strung between poles supported sheer UV-resistant polypropylene mesh $(2 \times 2 \mathrm{~cm}$, Easy Gardener, Waco, Tex.) draped over this frame, and guy wires stabilized cages to additional rebar anchors. Gaps in the mesh were stitched together and secured to the ground. Insects passed freely through this mesh, but birds were excluded.

\section{Arthropod sampling and analysis}

Arthropods were sampled by branch clipping (Basset et al. 1997; Johnson 2000). We haphazardly selected 510 branches from each focal plant and clipped and bagged the terminal $(\sim 50 \mathrm{~cm})$ twigs and foliage, the primary microhabitat exploited by many insectivorous birds in the Hawaiian Islands (Fretz 2000).

Foliage samples were collected in the morning hours, one block per day, and transported to the laboratory at Kilauea Field Station, Hawai'i Volcanoes National Park, for immediate processing. Foliage was shaken, beaten and sifted, and all arthropods were collected with an aspirator and stored in 70\% ethanol. Branch shaking and detritus sifting continued until no additional arthropods were observed. Foliage was separated from woody material, dried to constant mass, and weighed to milligram precision.

To limit the impact of destructive sampling, arthropods were collected from focal trees only before applying experimental treatments (25-28 August 1998) and at the conclusion of the 33 months study (16 April - 3 May 2001). The purpose of the initial sampling was to test the null hypothesis that there were no pre-existing plot differences prior to establishing treatments. The final collection period coincided with the nesting and fledging period of the most common passerines at the site (Baldwin 1953; Scott et al. 1986; Ralph and Fancy 1994), a time when avian demand for arthropods should be high, but before expected summer declines in arthropod numbers (D. Gruner, unpublished data).

All arthropods collected were counted and identified to species or assigned to operational morphospecies, based on morphological evidence and advice of taxonomists. Arthropods were classified by trophic levels (carnivores, detritivores, herbivores, and tourists) using evidence from personal observation, literature review, and communication with systematists. Carnivores included all spiders, cursorial hunters, and parasitoids; detritivores comprised saprophagic arthropods and grazers of litter, fungi, and microbes; herbivores consisted of sap feeders, gall-formers (mostly free living adults), wood-borers, and foliage chewers; and tourists were species known to be incidental or non-feeding on Metrosideros, or with unknown or highly omnivorous feeding habits.

Specimen data were managed using biodiversity collections database software (Colwell 1997). A taxonomic checklist (Nishida 2002) was used to classify species as introduced, native (including endemic and indigenous forms), or undetermined in cases where identification was impossible or status was unknown. A complete list of species collected in this study was published elsewhere (Gruner 2004a, b), and vouchers and bulk collections are deposited at the B.P. Bishop Museum, Honolulu.

\section{Species density and richness}

We report two indices of total and trophic level arthropod biodiversity: species load and rarified species richness. Each index emphasizes different components of community diversity while controlling for possible sampling bias. Although every effort was made to collect similar sized clipping samples, this was impossible in practice. Species load is one measure of species density, which records the number of species per unit habitat. In this case the observed species richness was standardized by the dry foliage biomass collected with each sample (per $100 \mathrm{~g}$ dry mass). Plot level species load was obtained by averaging tree-level subsamples within plots.

Increased species number is expected as a random consequence of larger pools of individuals (Gotelli and Colwell 2001). Fertilization and bird exclusion did increase the densities of some Metrosideros arthropod groups (Gruner 2004b). Therefore, rather than report raw species number, rarefaction was used to estimate 'expected species richness' (hereafter, 'richness') at constant total abundance (Gotelli and Colwell 2001). Species recorded were pooled across trees within plots, and Monte Carlo simulations were run for 1,000 iterations on each plot using EcoSim freeware (Gotelli and 
Entsminger 2002). Plots were compared across a standard abundance threshold for each trophic group in initial (all arthropods: only 40 individuals) and final samples (all arthropods: 130 individuals; detritivores: 75; herbivores: 14; carnivores: 18). Abundance thresholds were selected to include values observed in $90 \%$ of the plots; there were up to three outlying plots with lower abundances within each trophic comparison. For these outlying plots, the observed species number was used (Kneitel and Miller 2002). Examination of rarefaction plots revealed no changes in relative trends (e.g. crossing lines) across the higher abundance ranges observed in some plots. Results for Shannon's index of diversity (Magurran 1988) were qualitatively similar to rarified richness and are not reported.

Species load and richness were analyzed with mixed general linear models (GLM) using type III sums of squares in PROC MIXED (SAS 2001). The fertilization and bird exclusion factors were treated as fixed, and the random block term accounted for spatial environmental heterogeneity. All two-way interactions were included in the GLM in accordance with model 1 of Newman et al. (1997). The main fixed effects were tested using the mean square of the corresponding block interaction term as the denominator of the $F$-ratio, rather than the mean squared error. This had a conservative effect on $P$-values, as the mean squares of the block interactions were usually larger than the error terms in these models.

Initial and final collections were analyzed with separate GLMs. Repeated measures analyses were not pursued because of (1) separation in time by $>2.5$ years between sampling bouts, and (2) disparities in the mean mass of foliage collections from initial and final samples. Low arthropod abundances in the small initial collections placed them on the steeply increasing region of rarefaction curves with highly uncertain richness estimates, whereas the curves from larger final collections reached asymptotic regions where treatment comparisons were more reliable. Response data were natural logtransformed when necessary to meet assumptions of normality and homoscedasticity. For final collections, linear models were tested for species load and expected species richness of all arthropods and for carnivores, herbivores, and detritivores separately. For initial collections, we tested only the total arthropod response variables due to empty cells for some trophic levels. Multiple comparisons, using the joint significance level of $\alpha=0.05$, were run for each GLM using the TukeyKramer test.

\section{Species composition}

Distance-based multivariate techniques were used to test for treatment effects on species composition. Abundance data were pooled across trees within plots and natural log-transformed $(x+1)$, which reduced the influence of a few, highly abundant but small-bodied species (Gruner 2004b). Species abundances were then standardized by dividing by plot total abundance sums (relativization), and distance matrices were calculated using the Euclidean distance measure. Relativization further reduced the influence of altered abundances caused in part by treatments, which were reported in a separate paper (Gruner 2004b), and focused instead on compositional differences (McCune and Grace 2002).

We used nonparametric multivariate analysis of variance (NPMANOVA) to test the influence of treatments on community species composition (Anderson 2001b; McArdle and Anderson 2001). This method allows hypotheses tests and analysis of symmetric distance matrices in ANOVA designs using a pseudo- $F$ ratio and $P$-value determined by permutation (Anderson 2001a). The model design matrix described above for GLM analysis was assembled with the same parameterization and tested using DISTLM software (Anderson 2000). For each trophic level, 999 permutations under the reduced model were run to estimate $P$-values for all 2-way factor combinations. We tested the full community and a restricted dataset excluding all species with only a single occurrence (singletons), but results were similar qualitatively and only the former are presented.

To visualize community composition of plots in species space, we used canonical analysis of principal coordinates, which constrains ordinations by a priori hypotheses ('CAP'; Anderson and Willis 2003). The CAP procedure may uncover patterns masked by variability in unconstrained ordinations, but guards against spurious results created by over parameterization (Anderson and Willis 2003). We collapsed factorial treatments into a single variable with eight replicates in each of four levels (control, fertilization only, bird exclusion only, and both fertilization and bird exclusion). As with NPMANOVA procedures, Euclidean distance was calculated on natural log-transformed $(x+1)$, relativized data matrices for all ordinations. The procedure distilled distance matrices into orthogonal axes $m$ (principal coordinates), the number of which were chosen using misclassification rates to groups in a 'leave-one-out' procedure (Anderson and Willis 2003). The null hypothesis of no difference in multivariate location among treatment levels was tested by calculating the trace statistic of canonical discriminant analysis and obtaining a $P$-value with 999 permutations in CAP software (Anderson 2003).

\section{Results}

Sampling considerations

In total, 119 species from 14 arthropod orders were collected from $M$. polymorpha in initial and final collections, 68 of these in 1998 and 108 in 2001 (Gruner 2004b). Of these species, 25 were classified as herbivorous, 24 were detritivorous, 54 were carnivorous (28 parasitoids, 26 predators), and 16 were tourists or 
undetermined. Over half of these species (65) were considered native (all endemic to the Hawaiian Islands), 33 were introduced, and 21 were cryptogenic. The majority of herbivorous individuals and species were native, but higher proportions of detritivores and carnivores were alien species (Fig. 1).

Sampling effort contributed to the species richness observed. Initial foliage collections were smaller than final collections because of the need to minimize destructive sampling at the outset. Although average density and biomass were similar among sampling periods (Gruner 2004b), absolute dry mass of foliage collections, absolute arthropod abundance, and observed species richness were lower in initial collections.

In addition, there was a minor difference in the amount of foliage collected per tree from plots of each treatment in 2001 (1-way ANOVA, $F_{3,84}=3.67$, $P=0.015)$. Post-hoc comparisons demonstrated a slightly larger foliage sample in caged treatments relative
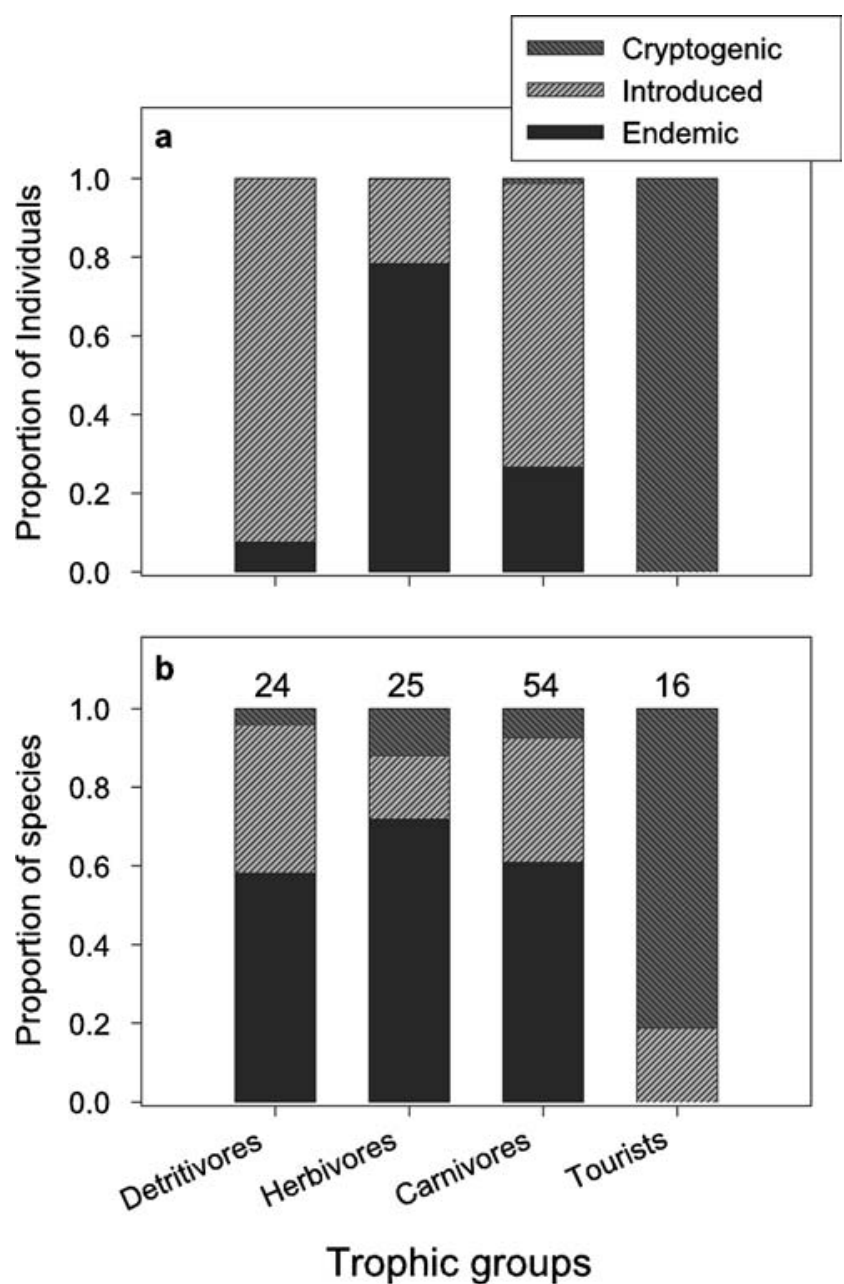

Fig. 1 Proportion of a total individuals and $\mathbf{b}$ total arthropod species across four trophic groups (detritivores, herbivores, carnivores, tourists) that were native (endemic), introduced, and cryptogenic. Totals were pooled from initial (1998) and final (2001) collections; numbers above bars in b represent total richness within trophic groups to controls [least-squares means $(\mathrm{g}) \pm 16.0 \mathrm{SE}$, control: 211.2; cage: 260.0; Tukey's HSD, adjusted $P=0.021$ ]. There was a significant, but weak positive relationship between the dry mass of foliage sampled and the total number of species observed $\left(R^{2}=7.0 \% ; \quad d f=87\right.$; $P=0.012$ ). One sample from a small tree in a control plot yielded only $41 \mathrm{~g}$ of foliage and four arthropod species [mean foliage mass $(\mathrm{g}) \pm \mathrm{SE}=221.3 \pm 6.5$; mean species observed $16.9 \pm 0.6]$. When this leverage point was removed, the regression was no longer significant $\left(R^{2}=3.9 \% ; d f=86 ; P=0.068\right)$. Nevertheless, we present two alternate indices for species diversity to account for variable effort in sampling both substrate and individual arthropods.

\section{Species load and richness}

Mixed model GLM analysis of initial collections showed virtually no significant differences in species load or rarified richness. In the sole exception, total richness was significantly higher only in plots that were later fertilized and caged $\left(F_{1,7}=10.51, P=0.014\right)$.

After 33 months, total species load was elevated in fertilized plots (Fig. 2a; $F_{1,7}=7.54, P=0.029$ ), although this effect was spatially variable (fert. $\times$ block: $F_{7,7}=5.25, P=0.022$ ). No other factors significantly affected total species load, and no total richness effects were evident at all (Fig. 2b). Detritivore species load was not affected by experimental factors (Fig. 2c), but richness was reduced by fertilization (Fig. 2d; $\left.F_{1,7}=15.50, \quad P=0.006\right)$ as abundances increased and evenness decreased (Gruner 2004b). In contrast, fertilization also influenced herbivores, but species load increased (Fig. 2e; $F_{1,7}=13.10, P=0.009$ ), while richness was unchanged (Fig. 2f; $F_{1,7}=2.18, P=0.183$ ). The effect of fertilization on herbivore species load was reduced marginally when plots were also caged $\left(F_{1,7}=4.92, P=0.062\right)$. Carnivore species load increased significantly in fertilized treatments (Fig. $2 \mathrm{~g} ; F_{1,7}=5.94$, $P=0.045$ ), but richness did not differ (Fig. 2h; $\left.F_{1,7}=0.92, P=0.369\right)$. Carnivore species load increased more than additively when fertilized and caged $\left(F_{1,7}=7.11, P=0.032\right)$, while richness was depressed in unfertilized, caged plots $\left(F_{1,7}=60.43, P<0.001\right)$. The cage factor alone did not change either diversity measure.

Rank abundance of species within trophic levels and across treatments (Magurran 1988) generally were consistent with expectations of the log-series distribution $\left(\chi^{2}, P>0.05\right)$, but were distinct from geometric series, lognormal, and broken-stick models $\left(\chi^{2}, P<0.001\right)$. However, herbivore dominance relationships were more equitable across species than either detritivores or carnivores (Fig. 3), with assemblages from control, fertilized only, and caged only treatments not appreciably different than the broken-stick model (control: $\chi^{2}=4.08$, $P=0.944$; fert.: $\chi^{2}=8.56, P=0.575$; cage: $\chi^{2}=18.47$, $P=0.048$; both: $\chi^{2}=32.43, P=0.0003$ ). 

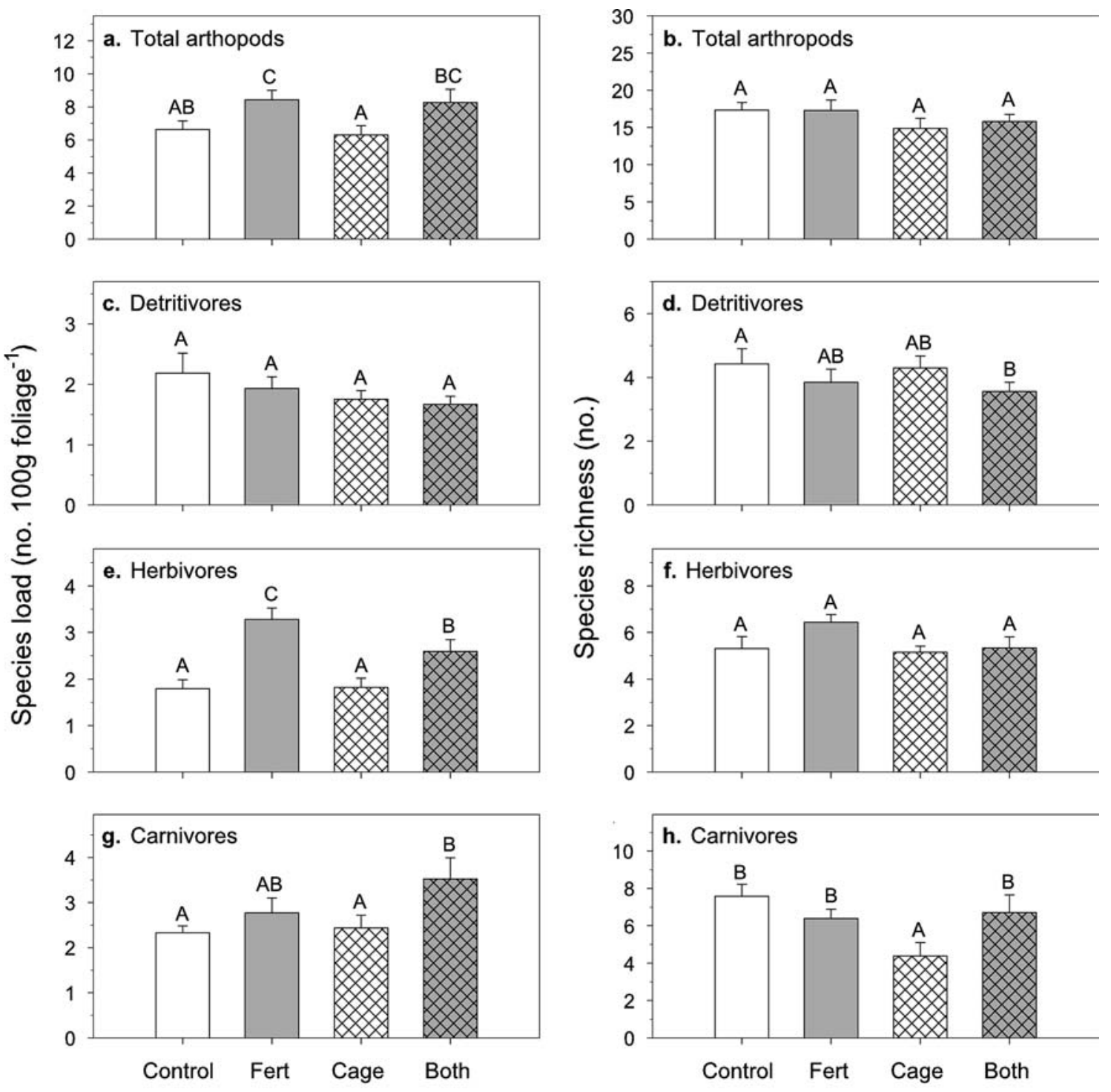

\section{Treatment}

Fig. 2 Species load and richness of $\mathbf{a}, \mathbf{b}$ total arthropods and three arthropod trophic levels (c, d detritivores, e, $\mathbf{f}$ herbivores, $\mathbf{g}, \mathbf{h}$ carnivores) in response to experimental fertilization (Fert), bird exclusion (Cage), and combined (Both) treatments, means + 1SE. Species load was the average number of species observed per $100 \mathrm{~g}$ dry foliage biomass. Species richness was computed by Monte Carlo

\section{Species composition}

Nonparametric MANOVA analyses of Euclidean distance matrices revealed no significant differences in initial community composition. However, both fertilization and cage treatments altered final arthropod species composition (fert.: pseudo- $F_{1,7}=3.149, P=0.003$; cage: pseudo- $\left.F_{1,7}=2.851, P=0.013\right)$. These effects were driven in part by changes observed for carnivores, which also responded significantly to fertilization and cage treatments (fert.: pseudo- $F_{1,7}=4.140, P=0.005$; cage: pseudo- $\left.F_{1,7}=5.118, P=0.005\right)$. The random block term was also significant for the total assemblage and for carni- individual-based rarefaction at uniform abundance thresholds at the plot level (Gotelli and Entsminger 2002). Shaded bars are fertilized treatments, and hatched bars represent bird exclusion treatments. Uppercase letters denote significantly different comparisons tested by Tukey's H.S.D. (joint $\alpha=0.05$ )

vores, indicating spatial variability in these responses (all: pseudo- $F_{7,7}=1.531, P=0.014$; carnivores: pseudo$\left.F_{7,7}=1.982, P=0.013\right)$. There were no significant changes in species composition of detritivores or herbivores.

Data manipulations of species abundance matrices were intended to reduce inordinate influence of highly abundant species as well as the species rarely observed. SIMPER analysis, which ranks the importance of each species in analytic outcomes (Clarke 2001), indicated that standardizations and log transformations had their intended effect. Before adjustments, the most abundant five species accounted for an average of $79.2 \%$ of the plot-level dissimilarity among treatments in $2001(n=6$ 

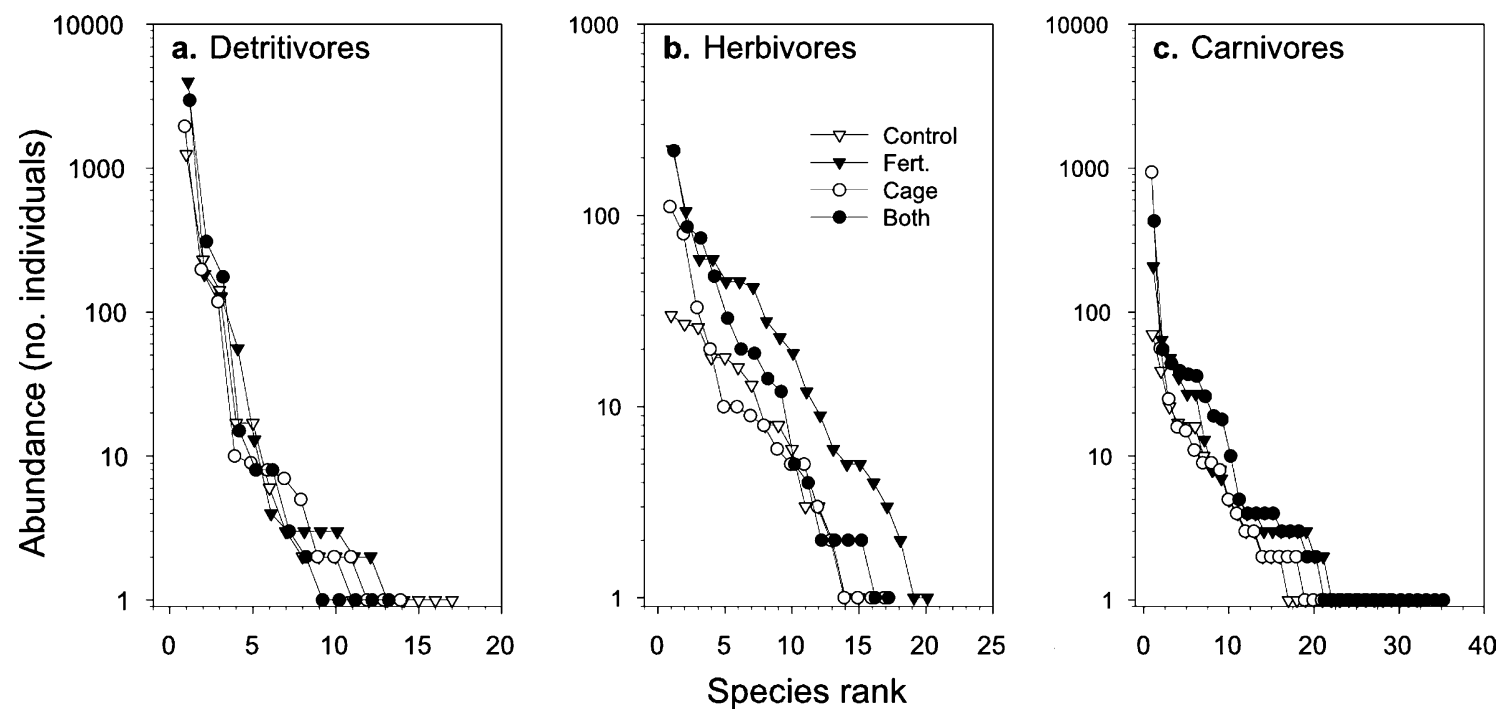

Fig. 3 Rank abundance curves for trophic level subsets under each treatment: a detritivores, b herbivores, and c carnivores. The plotted points are the pooled abundances of species from all replicates of each treatment, ranked in descending order of

abundance. Symbols are as follows: control (open triangle), fertilization only (filled triangle), caged only (open circle), and both fertilized and caged (filled circle)

comparisons). After standardization, these same five species accounted for $28.0 \%$ of the dissimilarity, whereas an average of 26 species accounted for the same $79 \%$. Furthermore, standardizations produced conservative treatment results. Without standardization, for example, both the fertilization and cage main effects for carnivores were more strongly significant $(P<0.001)$, as was the fertilization effect for herbivores $(P=0.010)$.

We explored the effects of rare species by removing all singletons (29 species observed only once in 2001) and repeating nonparametric analyses. Singleton removal did not alter qualitative treatment differences in species composition, thus these results are not discussed further. However, removal of the most abundant species had variable effects on statistical results. The collembolan Salina celebensis Schaeffer (Entomobryidae) was an order of magnitude more abundant than the next most abundant species, but it was ubiquitous, and its removal had no effect on total arthropod or detritivore-only statistical trends. However, the most abundant carnivore was the spider Achaearanea cf. riparia Blackwall (Theridiidae), primarily found in caged plots in final collections. When this species was removed from carnivorelevel analyses, all previously significant compositional differences disappeared, although the fertilization effect remained a strong trend (fert.: pseudo- $F_{1,7}=2.53$, $P=0.069$ ). Similarly, $A$. riparia accounted for the significant cage effect in total arthropod composition and fertilization remained significant upon its removal (fert.: pseudo- $F_{1,7}=2.70, P=0.003$ ).

Strong clumping of plots within treatments emerged when the noise and redundancy of 108 species were reduced to principal coordinates (all arthropods: $m=9$ axes, $76.17 \%$ explained variation) and analyzed with CAP (Fig. 4; trace $=2.783, P=0.004$ ). The first axis explained the most variation and separated control plots from all treatment plots $\left(\delta_{1}^{2}=2.191\right)$, the second axis divided the levels of fertilization $\left(\delta_{2}^{2}=0.341\right)$, and the third axis separated the bird exclusion treatments $\left(\delta_{3}^{2}=0.250\right)$.

\section{Discussion}

Previous analyses and complementary studies have shown increased arthropod abundance across all trophic levels on fertilized Metrosideros polymorpha (Gruner 2004b; Gruner et al. 2005). The current study demonstrated that fertilization also increased the species load of herbivores, enemies, and all arthropods in aggregate (Fig. 2). However, the estimates of species richness from individual-based rarefaction did not increase with fertilization for any trophic group. Numerous studies have examined the diversity of herbivorous or other arthropods in response to fertilization, but generalizations have been elusive (e.g., Hurd and Wolf 1974; Kirchner 1977; Kajak 1981; Vince et al. 1981; Prestidge 1982; Strauss 1987; Sedlacek et al. 1988; Siemann 1998; Haddad et al. 2000). However, several of these studies observed higher abundance of sap-sucking Auchenorryncha and other herbivorous groups, but decreasing evenness and diversity as a small number of species emerged as dominant (Prestidge 1982; Sedlacek et al. 1988; Haddad et al. 2000).

Several dominant species in the M. polymorpha food web depressed rarefied species richness because they reduced the probability of finding other species in fixed random draws. Although detritivore species load did not increase in enriched plots, richness decreased significantly with fertilization. An introduced collembolan 

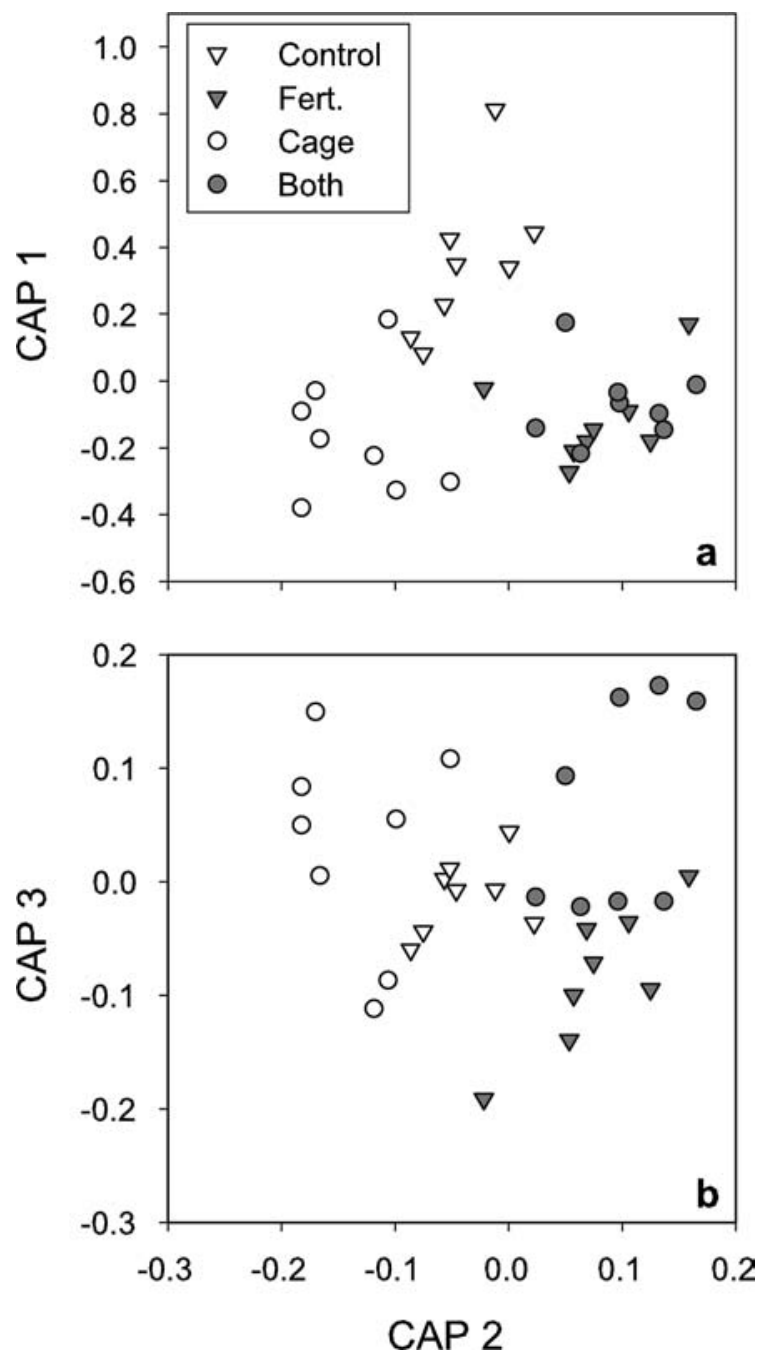

Fig. 4 Ordination diagrams of a axes 1 and 2, and $\mathbf{b}$ axes 2 and 3 from canonical analysis of principal coordinates. Species data were first transformed $(\ln x+1)$ and standardized by plot sums, then all Euclidean distances were calculated. The distance matrix was reduced to nine orthogonal principal coordinates and analyzed through a generalized discriminant analysis (CAP), constrained by collapsing fertilization and cage treatments into one factor with four levels. Symbols are as follows: control (triangle), fertilization only (filled triangle), caged only (open circle), and both fertilized and caged (filled circle)

(Salina celebensis) comprised a large proportion of this response, although it was so ubiquitous that it did not cause differential changes in composition among treatments (see also Gruner et al. 2005). The congeneric species Salina banksi MacGillivray can also be a numerical dominant in tree canopies of humid Mexican forests, as it was 30 times more abundant on average than all other collembolans (Palacios-Vargas and Castaño-Meneses 2003). Christiansen and Bellinger (1992) assert that this species is the most abundant terrestrial animal in the Hawaiian Islands, highlighting the importance of individualistic species traits in determining community responses to top-down and bottom-up variation.
Composition of the carnivore assemblage shifted significantly as a consequence of bird removal. The topdown treatment did not directly alter species load of any trophic group (Fig. 2). However, carnivore richness decreased with increasing abundance of a single outbreaking species released from bird predation, the introduced theridiid spider Achaearanea cf. riparia (Blackwall) (Gruner 2005). These results are consistent with empirical studies from aquatic periphyton communities (Hillebrand 2003), and expectations from keystone species models, where predators mediate diversity by suppressing the most abundant edible taxa (Leibold 1996). Despite the ubiquity of A. riparia in caged plots, carnivore richness was higher when plots were also fertilized, possibly because fertilized plots contained a greater abundance of prey or greater diversity of habitat types for native sit-and-wait, ambush, and hunting spiders (Rypstra 1983). Top-down effects on richness of other trophic levels may not have emerged because insectivorous birds prey selectively on only a subset of all taxa in this community (Baldwin 1953; Gruner 2004b; C. Ralph and C.J. Ralph, unpublished data; R. Peck et al., unpublished data).

No similar depression of herbivore richness was observed, even though fertilization increased herbivore species load (Fig. 2). Unlike the carnivores and detritivores, no single or small minority of species emerged as dominants after experimental perturbation (Fig. 3). As herbivore abundance increased with fertilization, additional rare species colonized or persisted, but without altering equitability patterns within treatments (Pielou's $J$ ' evenness, overall mean \pm SE: $0.83 \pm 0.02$, all $F$-tests n.s.). Observed herbivores were primarily native, specialized Metrosideros feeders, not transients potentially spilling over from other local host plant species (Fig. 1; Gruner 2004a). It is impossible to speculate whether this distinct herbivore assemblage response was a result of the tight associations of specialists with this host plant, or whether this pattern should be expected more so for herbivores than for predators, parasitoids and detritivores. Nevertheless, the increased species load in this case is consistent with the hypothesis that productivity increases diversity by allowing rare species to exist in larger local populations on the resource base of higher quality or quantity (Siemann 1998; Srivastava and Lawton 1998).

Fertilization or nitrogen deposition often alters plant diversity and species composition (Naeem et al. 1996; Waide et al. 1999; Stevens et al. 2004; Suding et al. 2005), but many arthropod community studies have been unable to disentangle plant productivity from diversity (but see Siemann 1998). In this study, we concentrated on the fauna of a single dominant tree species to control for changes in plant community composition that occur with fertilization. However, intraspecific variation in plant traits, such as foliar pubescence or chemistry, can affect arthropod species composition from the bottom-up even while host species is held constant (Fritz and Price 1988; Dickson and 
Whitham 1996; Stiling and Rossi 1996; Cronin and Abrahamson 2001). Metrosideros polymorpha is variable in foliar morphology along altitudinal, edaphic, and successional gradients, and multiple pubescence classes are found within some populations (Corn and Hiesey 1973; Stemmermann 1983; James et al. 2004). Three $M$. polymorpha morphotypes corresponding to the described varieties glaberrima, polymorpha, and incana are sympatric at this mid-elevation site (Dawson and Stemmerman 1999; Gruner et al. 2005). Morphotypical pubescence on mature trees at this site did not respond plastically to fertilization, and in a separate study the community-wide effects of morphological variation were largely independent of fertilization (Gruner et al. 2005). Even so, countervailing responses to pubescence by different taxonomic groups within trophic levels may have diluted the top-down and bottom-up treatment responses seen with aggregate indices of richness, which do not account for species turnover (Hare and Elle 2002; Gruner et al. 2005).

\section{Conclusions}

The results of this press experiment indicate that topdown and bottom-up mechanisms can influence local richness and species composition of forest arthropods. Consistent with results from several recent factorial manipulations (Kneitel and Miller 2002; Dyer and Letourneau 2003; Hillebrand 2003), we found only slight evidence for interaction among nutrient addition and bird exclusion treatments on arthropod richness within trophic levels. Fertilization effects were more prevalent across trophic levels (Fig. 4; Gruner 2004b). Increases in species densities were driven by increased overall abundance, particularly in generalist species that were already common, thus reducing evenness and richness. Birds increased richness by selectively removing abundant carnivorous arthropods, with a particularly strong impact on one introduced spider species (Gruner 2005). This result further highlights the individuality of species traits in creating community pattern (Leibold 1996; Davis et al. 1998).

Communities are typically comprised of a few common species and many rare species (Fisher et al. 1943; Preston 1962; Hubbell 2001). Nowhere is this more apparent than in tropical forest arthropod communities, where metacommunity dynamics and regional colonization rates may dictate total local richness more than biotic interactions (Stirling and Wilsey 2001; Basset et al. 2003). These large proportions of rare, migrant species might obscure the biotic interactions of abundant core species within community samples (Magurran and Henderson 2003). In this study, however, experimental press manipulations drove population changes of several common species that, in turn, drove trophic level richness, whereas statistical control of rare species did not change treatment effects on composition. The experiment simulated anthropogenic extinction of top consumers, which have been impacted disproportionately by humans (Duffy 2003), and increased nutrient deposition, which is occurring worldwide even in areas remote from human activity (Jefferies and Maron 1997). These rapid but persistent ecosystem changes may favor widespread, generalized species over locally specialized species, and thus may facilitate invasion by introduced species and reduced local diversity.

Acknowledgements We thank the Hawai'i Division of Forestry and Wildlife for field research permits and access, and D. Foote and research staff at Hawai'i Volcanoes National Park for logistical assistance and laboratory space. We are grateful to G. Bodner, R. Cabin, S. Cordell, L. Durand, N. Everett, D. Feinholz, P. Hart, S. Hight, R. Langston, P. Nilsson, and especially K. Heckmann, L. Wilson, S. McDaniel, and E. McDaniels for providing invaluable field assistance. The following people graciously assisted with arthropod identifications: K. Arakaki, M. Arnedo, M. Asche, J. Beatty, J. Garb, M. Gates, G. Gibson, R. Gillespie, J. Huber, E. Mockford, J. Noyes, D. Percy, D. Polhemus, D. Preston, A. Samuelson, C. Tauber, and A. Vandergast. We thank R. Kinzie, R. Forkner, J. Ewel, D. Strong, T. Crist, O. Schmitz and an anonymous reviewer for critical comments on the manuscript. D.S.G. received funding from training grants from the John D. and Catherine T. MacArthur Foundation and NSF DGE-9355055 \& DUE-9979656 to the Center for Conservation Research and Training at the University of Hawai'i at Mānoa, an E.P.A Science to Achieve Results (STAR) graduate fellowship, and research grants from Sigma Xi, the Hawai'i Audubon Society, the Watson T. Yoshimoto Foundation, the ARCS Foundation, and the NSF DDIG program (DEB-0073055).

\section{References}

Abrams PA (1995) Monotonic or unimodal diversity-productivity gradients: what does competition theory predict? Ecology 76:2019-2027

Anderson MJ (2000) DISTLM: a FORTRAN computer program to calculate a distance-based multivariate analysis for a linear model. Department of Statistics, University of Auckland, Auckland, New Zealand

Anderson MJ (2001a) Permutation tests for univariate or multivariate analysis of variance and regression. Can $\mathbf{J}$ Fish Aquat Sci 58:626-639

Anderson MJ (2001b) A new method for non-parametric multivariate analysis of variance. Austral Ecol 26:32-46

Anderson MJ (2003) CAP: a FORTRAN computer program for canonical analysis of principal coordinates. Department of Statistics, University of Auckland, Auckland, New Zealand

Anderson MJ, Willis TJ (2003) Canonical analysis of principal coordinates: a useful method of constrained ordination for ecology. Ecology 84:511-525

Baldwin PH (1953) Annual cycle, environment and evolution in the Hawaiian honeycreepers (Aves: Drepaniidae). Univ Calif Publ Zool 52:285-398

Basset Y, Springate ND, Aberlenc HP, Delvare G (1997) A review of methods for sampling arthropods in tree canopies. In: Stork NE, Adis J, Didham RK (eds) Canopy Arthropods. Chapman and Hall, London, pp 27-52

Basset Y, Novotný V, Miller SE, Kitching RL (2003) Arthropods of tropical forests: spatio-temporal dynamics and resource use in the canopy. Cambridge University Press, London

Cardinale BJ, Palmer MA, Ives AR, Brooks SS (2005) Diversityproductivity relationships in streams vary as a function of the natural disturbance regime. Ecology 86:716-726

Christiansen K, Bellinger P (1992) Insects of Hawaii, vol. 15: Collembola. University of Hawaii Press, Honolulu, Hawaii 
Clarke KR (2001) PRIMER for Windows, Version 5.0. PRIMERE, Plymouth, UK

Colwell RK (1997) Biota: the Biodiversity Database Manager, Version 1.0. Sinauer, Sunderland, Mass.

Cordell S, Goldstein G, Meinzer FC, Vitousek PM (2001) Morphological and physiological adjustment to $\mathrm{N}$ and $\mathrm{P}$ fertilization in nutrient-limited Metrosideros polymorpha canopy trees in Hawaii. Tree Physiol 21:43-50

Corn CA, Hiesey WM (1973) Altitudinal variation in Hawaiian Metrosideros. Am J Bot 60:991-1002

Cronin JT, Abrahamson WG (2001) Goldenrod stem galler preference and performance: effects of multiple herbivores and plant genotypes. Oecologia 127:87-96

Davis AJ, Lawton JH, Shorrocks B, Jenkinson LS (1998) Individualistic species responses invalidate simple physiological models of community dynamics under global environmental change. J Anim Ecol 67:600-612

Dawson JW, Stemmerman L (1999) Metrosideros Banks ex Gaertn. In: Wagner WL, Herbst DR, Sohmer SH (eds) Manual of the flowering plants of Hawaii, 2nd edn, vol 1. Bernice P Bishop Museum Press, Honolulu, HI, pp 964-970

De Angelis DL (1980) Energy flow, nutrient cycling, and ecosystem resilience. Ecology 61:764-771

Dickson LL, Whitham TG (1996) Genetically-based plant resistance traits affect arthropods, fungi, and birds. Oecologia 106:400-406

Duffy JE (2003) Biodiversity loss, trophic skew and ecosystem functioning. Ecol Lett 6:680-687

Dyer LA, Letourneau DK (2003) Top-down and bottom-up diversity cascades in detrital vs. living food webs. Ecol Lett 6:60-68

Fisher RA, Corbet AS, Williams CB (1943) The relation between the number of species and the number of individuals in a random sample of an animal population. J Anim Ecol 12:42-58

Foster JT (2005) Exotic bird invasion into forests of Hawaii: demography, competition, and seed dispersal. Dissertation, University of Illinois at Urbana-Champaign

Fretz JS (2000) Relationship of canopy arthropod prey to distribution and life history of the Hawai'i 'akepa. PhD Dissertation, University of Hawai'i at Manoa, Honolulu, Hawaii

Fritz RS, Price PW (1988) Genetic variation among plants and insect community structure: willows and sawflies. Ecology 69:845-856

Giambelluca TW, Nullet MA, Schroeder TA (1986) Rainfall atlas of Hawaii. Department of Land and Natural Resources, State of Hawaii, Honolulu, HI, USA

Gotelli NJ, Colwell RK (2001) Quantifying biodiversity: procedures and pitfalls in the measurement and comparison of species richness. Ecol Lett 4:379-391

Gotelli NJ, Entsminger GL (2002) EcoSim: Null Models Software for Ecology, Version 7. Acquired Intelligence Inc. \& KeseyBear, Burlington, VT

Gruner DS (2004a) Arthropods from 'ōhi'a lehua (Myrtaceae: Metrosideros polymorpha), with new records for the Hawaiian Islands. Bish Mus Occas Pap 78:33-52

Gruner DS (2004b) Attenuation of top-down and bottom-up forces in a complex terrestrial community. Ecology 85:3010-3022

Gruner DS (2005) Biotic resistance to an invasive spider conferred by insectivorous birds on the island of Hawai'i. Biol Invasions 7:541-546

Gruner DS, Taylor AD, Forkner RE (2005) The effects of foliar pubescence and nutrient enrichment on arthropod communities of Metrosideros polymorpha (Myrtaceae). Ecol Entomol $30: 428-443$

Haddad NM, Haarstad J, Tilman D (2000) The effects of long-term nitrogen loading on grassland insect communities. Oecologia 124:73-84

Hare JD, Elle E (2002) Variable impact of diverse insect herbivores on dimorphic Datura wrightii. Ecology 83:2711-2720

Hillebrand $\mathrm{H}$ (2003) Opposing effects of grazing and nutrients on diversity. Oikos 100:592-600
Holt RD, Grover J, Tilman D (1994) Simple rules for interspecific dominance in systems with exploitative and apparent competition. Am Nat 144:741-771

Holt RD, Lawton JH (1994) The ecological consequences of shared natural enemies. Annu Rev Ecol Syst 25:495-520

Hubbell SP (2001) The unified neutral theory of biodiversity and biogeography. Princeton University Press, Princeton, NJ

Hurd LE, Wolf LL (1974) Stability in relation to nutrient enrichment in arthropod consumers of old-field successional ecosystems. Ecol Mono 44:465-482

Huston MA (1994) Biological diversity: the coexistence of species on changing landscapes. Cambridge University Press, Cambridge, UK

Hutchinson GE (1959) Homage to Santa Rosalia, or why are there so many kinds of animals? Am Nat 93:145-159

James SA, Puttock CF, Cordell S, Adams RP (2004) Morphological and genetic variation in Metrosideros polymorpha (Myrtaceae) on Hawaii. New Zeal J Bot 42:263-270

Jefferies RL, Maron JL (1997) The embarassment of riches: atmospheric deposition of nitrogen and community and ecosystem processes. Trends Ecol Evol 12:74-78

Johnson MD (2000) Evaluation of an arthropod sampling technique for measuring food availability for forest insectivorous birds. J Field Ornithol 71:88-109

Kajak A (1981) Analysis of the effect of mineral fertilization on the meadow spider community. Ekol Pol 29:313-326

Kirchner TB (1977) The effects of resource enrichment on the diversity of plants and arthropods in a shortgrass prairie. Ecology 58:1334-1344

Kneitel JM, Miller TE (2002) Resource and top-predator regulation in the pitcher plant (Sarracenia purpurea) inquiline community. Ecology 83:680-688

Kondoh M (2001) Unifying the relationships of species richness to productivity and disturbance. Proc R Soc Lond B 268:269-271

Leibold MA (1996) A graphical model of keystone predators in food webs: trophic regulation of abundance, incidence, and diversity patterns in communities. Am Nat 147:784-812

MacArthur RH (1969) Patterns of communities in the tropics. Biol J Linn Soc 1:19-30

Magurran AE (1988) Ecological diversity and its measurement. Princeton University Press, Princeton, NJ

Magurran AE, Henderson PA (2003) Explaining the excess of rare species in natural species abundance distributions. Nature 422:714-716

McArdle BH, Anderson MJ (2001) Fitting multivariate models to community data: a comment on distance-based redundancy analysis. Ecology 82:290-297

McCune B, Grace JB (2002) Analysis of Ecological Communities. MJM Software, Gleneden Beach, OR

Menge BA, Sutherland JP (1987) Community regulation: variation in disturbance, competition, and predation in relation to environmental stress and recruitment. Am Nat 130:730-757

Mittelbach GG, et al. (2001) What is the observed relationship between species richness and productivity? Ecology 82:23812396

Mittelbach GG, Scheiner SM, Steiner CF (2003) What is the observed relationship between species richness and productivity? Reply. Ecology 84:3390-3395

Naeem S, Hakansson K, Lawton JH, Crawley MJ, Thompson LJ (1996) Biodiversity and plant productivity in a model assemblage of plant species. Oikos 76:259-264

Nishida GM (ed) (2002) Hawaiian Terrestrial Arthropod Checklist, 4th edn. Bishop Museum Press, Honolulu, HI

Paine RT (1966) Food web complexity and species diversity. Am Nat 100:65-75

Palacios-Vargas JG, Castaño-Meneses G (2003) Seasonality and community composition of springtails in Mexican forests. In Basset Y, Novotný V, Miller SE, Kitching RL (eds) Arthropods of tropical forests: spatio-temporal dynamics and resource use in the canopy. Cambridge University Press, London, pp 159169 
Perkins RCL (1903) Vertebrata. In: Sharp D (ed) Fauna Hawaiiensis. Cambridge University Press, Cambridge, pp 365-466

Prestidge RA (1982) The influence of nitrogenous fertilizer on the grassland Auchenorrhyncha (Homoptera). J Appl Ecol 19:735749

Preston FW (1962) The canonical distribution of commonness and rarity. Ecology 43:185-215; 410-432

Proulx M, Mazumder A (1998) Reversal of grazing impact on plant species richness in nutrient-poor vs. nutrient-rich ecosystems. Ecology 79:2581-2592

Raich JW, Russell AE, Crews TE, Farrington H, Vitousek PM (1996) Both nitrogen and phosphorus limit plant production on young Hawaiian lava flows. Biogeochemistry 32:1-14

Raich JW, Russell AE, Vitousek PM (1997) Primary productivity and ecosystem development along an elevational gradient on Mauna Loa, Hawaii. Ecology 78:707-721

Ralph CJ, Fancy SG (1994) Timing of breeding and molting in six species of Hawaiian honeycreepers. Condor 96:151-161

Rosenzweig ML, Abramsky Z (1993) How are diversity and productivity related? In: Ricklefs RE, Schluter D (eds) Species diversity in ecological communities: historical and geographical perspectives. University of Chicago Press, Chicago, IL, pp 52-65

Rosenzweig ML (1995) Species diversity in space and time. Cambridge University Press, Cambridge, UK

Rypstra AL (1983) The importance of food and space in limiting web-spider densities; a test using field enclosures. Oecologia 59:312-316

SAS (2001) SAS for Windows, Version 8.02. SAS Institute, Cary, N.C.

Schoener TW, Spiller DA (1996) Devastation of prey diversity by experimentally introduced predators in the field. Nature 381:691-694

Scott JM, Mountainspring S, Ramsey FL, Kepler CB (1986) Stud Avian Biol, vol. 9: Forest bird communities of the Hawaiian Islands: their dynamics, ecology, and conservation. Cooper Ornithological Society, Los Angeles, Calif.

Sedlacek JD, Barrett GW, Shaw DR (1988) Effects of nutrient enrichment on the Auchenorrhyncha (Homoptera) in contrasting grassland communities. J Appl Ecol 25:537-550

Siemann E (1998) Experimental tests of effects of plant productivity and diversity on grassland arthropod diversity. Ecology 79:2057-2070

Sih A, Crowley P, Mcpeek M, Petranka J, Strohmeier K (1985) Predation, competition, and prey communities: a review of field experiments. Annu Rev Ecol Syst 16:269-311
Spiller DA, Schoener TW (1998) Lizards reduce spider species richness by excluding rare species. Ecology 79:503-516

Srivastava DS, Lawton JH (1998) Why more productive sites have more species: an experimental test of theory using tree-hole communities. Am Nat 152:510-529

Stein JD (1983) Insects infesting Acacia koa (Legumosae) and Metrosideros polymorpha (Myrtaceae) in Hawaii: an annotated list. Proc Hawaii Entomol Soc 24:305-316

Stemmermann RL (1983) Ecological studies of Hawaiian Metrosideros in a successional context. Pac Sci 37:361-373

Stevens CJ, Dise NB, Mountford JO, Gowing DJ (2004) Impact of nitrogen deposition on the species richness of grasslands. Science 303:1876-1879

Stiling P, Rossi AM (1996) Complex effects of genotype and environment on insect herbivores and their enemies. Ecology 77:2212-2218

Stirling G, Wilsey B (2001) Empirical relationships between species richness, evenness, and proportional diversity. Am Nat 158:286-299

Strauss SY (1987) Direct and indirect effects of host-plant fertilization on an insect community. Ecology 68:1670-1678

Suding KN, et al. (2005) Functional- and abundance-based mechanisms explain diversity loss due to $\mathrm{N}$ fertilization. Proc Natl Acad Sci USA 102:4387-4392

Swift SF, Goff ML (2001) Mite (Acari) communities associated with 'ōhi'a, Metrosideros polymorpha (Myrtaceae), at Homo O Nà Pali and Kui'a natural area reserves on Kaua'i Island, Hawaiian Islands. Pac Sci 55:23-40

Tilman D (1986) A consumer-resource approach to community structure. Am Zool 26:5-22

van Riper C, III, Scott JM (1979) Observations on distribution, diet, and breeding of the Hawaiian thrush. Condor 81:65-71

Vince SW, Valiela I, Teal JM (1981) An experimental study of the structure of herbivorous insect communities in a salt marsh. Ecology 62:1662-1678

Waide RB, et al. (1999) The relationship between productivity and species richness. Annu Rev Ecol Syst 30:257-300

Whittaker RJ, Heegaard E (2003) What is the observed relationship between species richness and productivity? Comment. Ecology 84:3384-3390

Worm B, Lotze HK, Hillebrand H, Sommer U (2002) Consumer versus resource control of species diversity and ecosystem functioning. Nature 417:848-851

Wright DH (1983) Species-energy theory: an extension of speciesarea theory. Oikos 41:496-506 